Membership recruitment and membership retention programs will be initiated in the near future.

To reflect the broadening interest of the society in other related areas in the hospital, such as quality assurance and pharmacoepidemiology, the board proposed and the membership approved an amendment to the bylaws to change the name of the society from The Society of Hospital Epidemiologists of America to The Society for Hospital Epidemiology of America. In addition to the name change, the society will try to recruit epidemiologists and other scientists with an interest in these related disciplines and will provide a forum through its annual meeting for presentation of scientific data in these fields. Expansion of the scope of the society's interests to include these related fields has the goal of furthering the application of the science of hospital epidemiology to all areas concerned with the quality of healthcare.

The first year of the second decade will be filled with challenges, opportunities, and risks. Success in the pusuit of our new goals will depend, in large part, on the level of commitment of society members to these goals. The society will need firm support from its membership in the form of enthusiastic participation in the annual meeting, submssion of abstracts for presentation at the annual meeting, and submssion of manuscripts to Infection Control and Hospital Epidemiology. The membership will need to be prepared to participate in new educational programs and to assist in the recruitment of new members. Members of the society will need to make an effort to establish a collegial relationship with investigators in the related fields involved with quality of healthcare and to admit these scientists to society membership. Failure to accept these challenges and take advantage of the opportunities provided by a new relationship with the publisher of our journal and with the expertise and management resources provided by our new management firm may leave us at the crest of a hill with no fuel and no brakes. Several new societies with memberships interested in quality assurance and risk management have appeared. They have large memberships and annual national meetings. At least one society offers a certifying examination. We must be prepared to compete in this new environment. Our major resource is the collective expertise in science and epidemiology in our society. Our national meeting should be the national forum for the presentation of data on the "cutting edge" of science and epidemiology not only in hospital epidemiology and infection control, but also in closely related disciplines involved with improving the quality of healthcare. Our journal should be the most important source for those interested in keeping up with the science and epidmemiology of how to assure high quality healthcare.

The society became firmly established in the 1980s. In the 1990 s, it must compete on a new playing field. Interest in the quality of healthcare has greatly expanded, and many new workers have entered the field. The society should approach this new era with courage and flexibility. If we are to control our own destiny, we will have to expand our activities into these related areas of quality assessment and improvement. We have been working on improving the quality of healthcare for 20 years by preventing nosocomial infections. The society membership has a great advantage in experience with the application of science and epidemiology to the solution of problems that adversely impact on the quality of care. We should not only move in this new direction, but we should be prepared to set the example and show the way.

C. Glen Mayhall, MD President, SHEA

\title{
SHEA/CDC/AHA Training Program
}

The SHEA/Centers for

Disease Control (CDC) /American

Hospital Association (AI-IA)

Hospital Epidemiology Training

Program will be held May 16-19, 1991, in Chicago, Illinois. The course is intended for infectious disease fellows and new hospital epidemiologists. it emphasizes hands-on exercises in which participants work in small groups to detect, investigate, and control epidemiological problems encountered in the hospital setting. These working sessions are supplemented with lectures and seminars covering fundamental aspects of hospital epidemiology. Drs. Donald Goldmann, William Martone, and Robert Weinstein and Gina Pugliese, RN, MS, will co-chair the program. Meeting, hotel, and travel arrangements will be available through the AHA. The registration fee for this program is $\$ 495$. The registration fee for infectious disease fellows is $\$ 250$ if the application is accompanied by proof of training status. For registration, call the AHA (Phil Gordon): (312) 280-6764. 